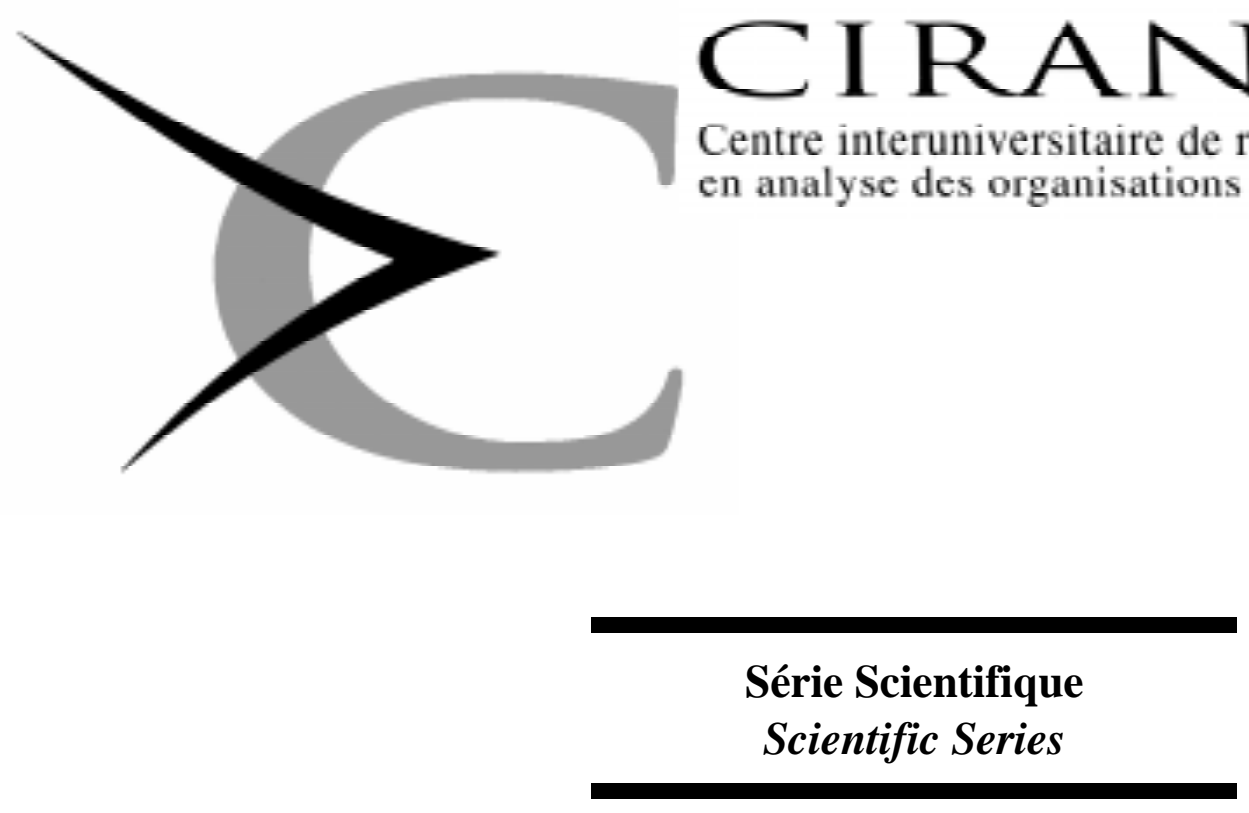

96s-17

\title{
Recent Advances in Numerical Methods for Pricing Derivative Securities
}

Mark Broadie, Jérôme Detemple 


\section{CIRANO}

Le CIRANO est une corporation privée à but non lucratif constituée en vertu de la Loi des compagnies du Québec. Le financement de son infrastructure et de ses activités de recherche provient des cotisations de ses organisations-membres, d'une subvention d'infrastructure du ministère de l'Industrie, du Commerce, de la Science et de la Technologie, de même que des subventions et mandats obtenus par ses équipes de recherche. La Série Scientifique est la réalisation d'une des missions que s'est données le CIRANO, soit de développer l'analyse scientifique des organisations et des comportements stratégiques.

CIRANO is a private non-profit organization incorporated under the Québec Companies Act. Its infrastructure and research activities are funded through fees paid by member organizations, an infrastructure grant from the Ministère de l'Industrie, du Commerce, de la Science et de la Technologie, and grants and research mandates obtained by its research teams. The Scientific Series fulfils one of the missions of CIRANO: to develop the scientific analysis of organizations and strategic behaviour.

\section{Les organisations-partenaires / The Partner Organizations}

-Ministère de l'Industrie, du Commerce, de la Science et de la Technologie.

-École des Hautes Études Commerciales.

-École Polytechnique.

-Université de Montréal.

-Université Laval.

-McGill University.

-Université du Québec à Montréal.

-Bell Québec.

-La Caisse de dépôt et de placement du Québec.

-Hydro-Québec.

-Fédération des caisses populaires de Montréal et de l'Ouest-du-Québec.

-Téléglobe Canada.

-Société d'électrolyse et de chimie Alcan Ltée.

-Avenor.

-Service de développement économique de la ville de Montréal.

- Raymond, Chabot, Martin, Paré

-Banque Nationale du Canada

Ce document est publié dans l'intention de rendre accessibles les résultats préliminaires de la recherche effectuée au CIRANO, afin de susciter des échanges et des suggestions. Les idées et les opinions émises sont sous l'unique responsabilité des auteurs, et ne représentent pas nécessairement les positions du CIRANO ou de ses partenaires.

This paper presents preliminary research carried out at CIRANO and aims to encourage discussion and comment. The observations and viewpoints expressed are the sole responsibility of the authors. They do not necessarily represent positions of CIRANO or its partners.

\section{ISSN 1198-8177}




\title{
Recent Advances in Numerical Methods for Pricing Derivative Securities
}

\author{
Mark Broadie ${ }^{\dagger}$, Jérôme Detemple
}

\begin{abstract}
Résumé / Abstract
Cet article présente une synthèse des méthodes numériques récentes utilisées pour l'évaluation des titres dérivés. Des méthodes qui s'appliquent aux options américaines standard sur actif sous-jacent unique, aux options avec barrières (barrier options) et rétroactives (lookback options), ainsi qu'aux options sur actifs multiples, sont passées en revue. Des critères de comparaison des diverses approches sont discutés. De nouveaux résultats numériques sont également présentés.

This paper provides a survey of recent numerical methods for pricing derivative securities. Methods for standard American options on a single underlying asset, barrier and lookback options and options on multiple assets are reviewed. Criteria for comparison of different approaches are discussed. New computational results are also presented.
\end{abstract}

Mots Clés : $\quad$ Méthodes numériques, options américaines, options avec barrières, options rétroactives, critères de comparaison

Keywords : Numerical Methods, American Options, Barrier Options, Lookback Options, Criteria for Comparison

\footnotetext{
${ }^{\dagger}$ Columbia University Graduate School of Business

* McGill University Faculty of Management and CIRANO
} 


\section{Introduction}

In the past two decades there has been an explosion in the use of derivative securities by investors, corporations, mutual funds, and financial institutions. Exchange traded derivatives have experienced unprecedented growth in volume while "exotic" securities (i.e., securities with nonstandard payoff patterns) have become more common in the over-the-counter market. Using the most widely accepted financial models, there are many types of securities which cannot be priced in closed-form. This void has created a great need for efficient numerical procedures for security pricing.

Closed-form prices are available in a few special cases. One example is a European option (i.e., an option which can only be exercised at the maturity date of the contract) written on a single underlying asset. The European option valuation formula was derived in the seminal papers of Black and Scholes (1973) and Merton (1973). In the case of American options (i.e., options which can be exercised at any time at or before the maturity date) analytical expressions for the price have been derived, but there are no easily computable, explicit formulas currently available. Researchers and practitioners must then resort to numerical approximation techniques to compute the prices of these instruments. Further complications occur when the payoff of the derivative security depends on multiple assets or multiple sources of uncertainty. Analytical solutions are often not available for options with path-dependent payoffs and other exotic options.

In this paper we provide a survey of recent numerical methods for pricing derivative securities. Section 2 focuses on standard American options on a single underlying asset. Section 3 briefly treats barrier and lookback options. Options on multiple assets are covered in Section 4. New computational results are also presented.

\section{American Options on a Single Underlying Asset}

In the standard model for pricing options, the price of the underlying security is assumed to follow a lognormal process. To fix notation, suppose that the price of the underlying asset is $S_{t}$ at time $t$. Then $S_{t}$ satisfies

$$
d S_{t}=S_{t}\left[(\mu-\delta) d t+\sigma d W_{t}\right]
$$

where $W_{t}$ is a standard Brownian motion process. The parameter $\mu$ is the expected return of the asset, $\delta$ is the dividend rate, and $\sigma$ is the volatility of the asset price, which are all taken to be constant. In the standard model money can be invested in a riskfree asset which has a constant interest rate $r$. For an overview of this model in particular, and derivatives in general, see the textbooks by Cox and Rubinstein (1985), Hull (1993), Stoll and Whaley (1993), and Jarrow and Turnbull (1996).

We first consider a European call option with maturity $T$ and strike price $K$. This means that its payoff at expiration is $\left(S_{T}-K\right)^{+} .{ }^{1}$ The value of the European call option at time 0 can be written as

$$
C^{E}\left(S_{0}\right)=\mathbf{E}^{*}\left[e^{-r T}\left(S_{T}-K\right)^{+}\right]
$$

where $\mathbf{E}^{*}$ denotes the expectation relative to the risk-neutral process for $S_{t}$, i.e., where $r$ replaces $\mu$ in (2.1). This risk-neutral valuation approach was pioneered by Cox and Ross (1976); its theoretical foundations are identified and characterized in the seminal papers of Harrison and Kreps (1979) and Harrison and Pliska (1981). The solution to (2.2) was first derived in Black and Scholes (1973) and Merton (1973) and is given by

$$
C^{E}\left(S_{0}\right)=S_{0} N\left(d_{1}\right)-e^{-r T} K N\left(d_{2}\right)
$$

\footnotetext{
${ }^{1}$ The operator $x^{+}$denotes $\max (x, 0)$.
} 
with

$$
\begin{aligned}
& d_{1}=\frac{\ln \left(S_{0} / K\right)+\left(r+\frac{1}{2} \sigma^{2}\right) T}{\sigma \sqrt{T}} \\
& d_{2}=\frac{\ln \left(S_{0} / K\right)+\left(r-\frac{1}{2} \sigma^{2}\right) T}{\sigma \sqrt{T}}=d_{1}-\sigma \sqrt{T} .
\end{aligned}
$$

where $N(\cdot)$ denotes the standard normal cumulative distribution. This solution is considered closed-form because the cumulative normal distribution is easily computed. See Abramowitz and Stegun (1972) or Moro (1995) for methods to approximate the cumulative normal distribution. ${ }^{2}$

An American call option with maturity $T$ and strike price $K$ can be exercised at any time at or prior to maturity. Its payoff is $\left(S_{\tau}-K\right)^{+}$if it is exercised at time $\tau \leq T$. The value of the American call option at time 0 can be written as

$$
C\left(S_{0}\right)=\max _{\tau} \mathbf{E}^{*}\left[e^{-r \tau}\left(S_{\tau}-K\right)^{+}\right]
$$

where the max is over all stopping times $\tau \leq T$. For a rigorous justification of (2.6) as the appropriate pricing formula, see Bensoussan (1984) and Karatzas (1988). Finding the optimal stopping policy is equivalent to determining the points $\left(t, S_{t}\right)$ for which early exercise is optimal. The boundary which separates the early exercise region from the continuation region is the optimal exercise boundary. Analytical solutions in the case of call options with discrete dividends were derived in Roll (1977), Geske (1979), and Whaley (1981). Early work in the non-dividend American put case is given in Johnson (1983) and Blomeyer (1986). ${ }^{3}$

The literature concerning the numerical solution of equation (2.6) is vast. Major approaches include binomial (or lattice) methods, techniques based on solving partial differential equations, integral equations, variational inequalities, Monte Carlo simulation, and others. $^{4}$

The binomial method for the valuation of American options was introduced by Cox, Ross, and Rubinstein (1979). Trinomial methods have been proposed in Parkinson (1977) and Boyle (1988) and further analyzed in Omberg (1988). Other generalizations and variations of the binomial approach are given in Rendleman and Bartter (1979), Jarrow and

${ }^{2}$ Moro (1995) proposes the approximation

$$
N(x) \approx \begin{cases}0.5+x \frac{\sum_{i=0}^{2} a_{i} x^{2 i}}{\sum_{i=1}^{3} b_{i} x^{2 i}} & \text { when } 0 \leq x \leq 1.87 \\ 1-\left(\frac{\sum_{i=0}^{2} c_{i} x^{i}}{\sum_{i=0}^{3} d_{i} x^{i}}\right)^{16} & \text { when } 1.87<x<6 \\ 1 & \text { when } x \geq 6\end{cases}
$$

where $a_{0}=0.398942270991, a_{1}=0.020133760596, a_{2}=0.002946756074, b_{1}=0.217134277847, b_{2}=$ $0.018576112465, b_{3}=0.000643163695, c_{0}=1.398247031184, c_{1}=-0.360040248231, c_{2}=0.022719786588$, $d_{0}=1.460954518699, d_{1}=-0.305459640162, d_{2}=0.038611796258$, and $d_{3}=-0.003787400686$. Moro (1995) shows that this approximation, properly implemented, is faster and more accurate than previous methods. Proper implementation includes using multiplication rather than exponentiation wherever possible. For example, rather than computing $z=a x^{4}+b x^{2}+c$ using the power function, it is more efficient to compute $y=x * x$ and then $z=(a y+b) y+c$.

${ }^{3}$ The payoff of a put option is $\left(K-S_{\tau}\right)^{+}$if it is exercised at time $\tau \leq T$. McDonald and Schroder (1990) and Chesney and Gibson (1995) derive an interesting put-call symmetry result. They show that in the standard model (geometric Brownian motion setting), the value of an American call option with parameters $S, K, r, \delta, T$ is related to the value of an American put option by

$$
C(S, K, r, \delta, T)=P(K, S, \delta, r, T) .
$$

Thus, the American put price equals the American call price with the identification of parameters: $S \rightarrow K$, $K \rightarrow S, r \rightarrow \delta$, and $\delta \rightarrow r$.

${ }^{4} \mathrm{~A}$ comparison of some early methods is given in Geske and Shastri (1985). 
Rudd (1983), Hull and White (1988), Amin (1991), Trigeorgis (1991), Tian (1993), and Leisen and Reimer (1995). ${ }^{5}$ Implementation improvements are given in Kim and Byun (1994) and Curran (1995). Applications to computing price derivatives appear in Pelsser and Vorst (1994). A convergence proof for these types of lattice methods for pricing American options is provided in Amin and Khanna (1994). The convergence of the optimal exercise boundary is proved in Lamberton (1993). Convergence rates for European option pricing are given in Leisen and Reimer (1995). Empirical convergence rate evidence for American option pricing is provided in Broadie and Detemple (1995b). Analytical convergence rate bounds for American option pricing using binomial methods are derived in Lamberton (1995).

Black and Scholes (1973) and Merton (1973) showed that the price of any contingent claim, in particular a call option, must satisfy what is now called the Black-Scholes fundamental partial differential equation (PDE):

$$
\frac{\partial C(S, t)}{\partial t}+(r-\delta) S \frac{\partial C(S, t)}{\partial S}+\frac{1}{2} \sigma^{2} S^{2} \frac{\partial^{2} C(S, t)}{\partial S^{2}}-r C(S, t)=0 .
$$

subject to the appropriate boundary conditions. For an American option some of the boundary conditions are related to the early exercise event. Finite difference methods for the numerical solution of this PDE and its associated boundary conditions in the American option case were introduced in Schwartz (1977) and Brennan and Schwartz (1977, 1978). Convergence of the Brennan and Schwartz method is proved in Jaillet, Lamberton, and Lapeyre (1990) and Zhang (1995). Related numerical approaches include Courtadon (1982) and Hull and White (1990). The quadratic method of MacMillan (1986) and Barone-Adesi and Whaley (1987) and the method of lines of Carr and Faguet (1995) are based on exact solutions to approximations of the Black-Scholes PDE.

Geske and Johnson (1984) present an exact analytical solution for the American option pricing problem. They write the continuous option price as the sum of prices of simpler options which can be exercised only at discrete points in time. However, their formula is an infinite series involving multidimensional cumulative normals (that can only be evaluated approximately by numerical methods) and an unknown exercise boundary (which must also be determined numerically). In the same paper, Geske and Johnson (1984) introduced the method of Richardson extrapolation to the option pricing problem. Richardson extrapolation has also been used in Breen (1991), Bunch and Johnson (1992), Ho, Stapleton, and Subrahmanyam (1994), Huang, Subrahmanyam, and Yu (1995), and Carr and Faguet (1995). For an extensive treatment of Richardson extrapolation see Marchuk and Shaidurov (1983). Other extrapolation techniques (see, e.g., Press et al. 1992) have not been extensively tested in this context.

Jaillet, Lamberton, and Lapeyre (1990) introduced the variational inequality approach to American option pricing. A discretization of this formulation leads to a linear complementarity problem (LCP) which can be solved by linear programming-type methods (see Cottle, Pang, and Stone 1992 for a complete treatment of LCPs). Numerical results with this approach are given in Dempster (1994). For an overview of differential equations and variational inequality approaches to option pricing, see the textbook by Wilmott, Dewynne, and Howison (1993).

McKean (1965) first derived an integral representation of the option price. Kim (1990), Jacka (1991), and Carr, Jarrow, and Myneni (1992) derive an alternate integral representation which expresses the value of the American option as the value of the corresponding European option plus an integral which represents the present value of the gains from early

\footnotetext{
${ }^{5}$ There is also a large literature on lattice methods with alternative specifications of the stochastic process and for pricing interest rate sensitive securities. See, e.g., Nelson and Ramaswamy (1990), Hull and White (1994a, 1994b), Tian (1992, 1994), Amin (1995), Amin and Bodurtha (1995), and Li et al. (1995).
} 
exercise:

$$
C\left(S_{0}\right)=C^{E}\left(S_{0}\right)+\int_{s=0}^{T}\left[\delta S_{0} e^{-\delta s} N\left(d_{3}\left(S_{0}, B_{s}, s\right)\right)-r K e^{-r s} N\left(d_{4}\left(S_{0}, B_{s}, s\right)\right)\right] d s,
$$

where $C^{E}\left(S_{0}\right)$ is the corresponding European call option value, $B_{s}$ is the optimal exercise boundary, and

$$
\begin{aligned}
& d_{3}\left(S_{0}, B_{s}, s\right)=\frac{1}{\sigma \sqrt{s}}\left[\log \left(S_{0} / B_{s}\right)+\left(r-\delta+\frac{1}{2} \sigma^{2}\right) s\right] \\
& d_{4}\left(S_{0}, B_{s}, s\right)=d_{3}\left(S_{0}, B_{s}, s\right)-\sigma \sqrt{s}
\end{aligned}
$$

This representation can be used to solve for the optimal exercise boundary (see, e.g., Kim 1990). Numerical results using equation (2.9) are given in Kim (1994) and Huang, Subrahmanyam, and Yu (1995).

\subsection{Evaluation Criteria for Numerical Methods}

Numerical solution procedures can be compared on many dimensions. Important factors to consider when evaluating and choosing a solution algorithm include:

- Numerical accuracy

- Computation speed

- Error bounds or error estimates

- Algorithm complexity

- Flexibility

- Availability of price derivatives (the "Greeks")

- Memory/storage requirements

Accuracy and speed are often the most important of these factors. The accuracy of a method can be measured in many ways, including average or worst-case error measures. Speed requirements vary depending on the intended application. Are answers required in real-time? How many securities need to be priced? Do implied parameters (e.g., implied volatility) need to be computed? For example, algorithms used to generate daily risk reports may have less stringent speed requirements than those used in a real-time trading support system.

Many other factors are important in the design and implementation of numerical algorithms for security pricing. Since numerical methods generate only approximate answers, error estimates or exact error bounds are highly desirable. Although algorithm implementation seems like a one-time cost, in many real applications the solution procedures are continually modified and updated, e.g., to incorporate algorithm enhancements or to extend the algorithm to price new securities. For this reason, simple and straightforward algorithms are highly preferred to more complicated, difficult to implement methods. Similarly, flexible algorithms, i.e., those which are easily adapted to new securities, are desirable. In the options context, the "Greeks" are often as important to compute as the prices themselves. Hence, those algorithms which generate price derivatives as a by-product of the pricing calculation are desirable. Finally, computer memory and disk storage requirements can be important considerations in choosing an algorithm. (One reasonable, though not 
very elegant, approach to American option pricing is to precompute a large table of suitably parameterized option prices. Then the pricing procedure involves only table lookup and interpolation.)

We begin our analysis by giving a brief description of lattice methods and the approximation procedures proposed in Broadie and Detemple (1995b). We then present performance results for several methods which quantify the speed-accuracy tradeoff.

\section{$2.2 \quad$ Lattice Methods}

The idea of binomial (and other lattice) methods is to discretize the risk-neutral process specified in equation (2.1) and then to use dynamic programming to solve for the option price. A three-step tree is illustrated in Figure 1.

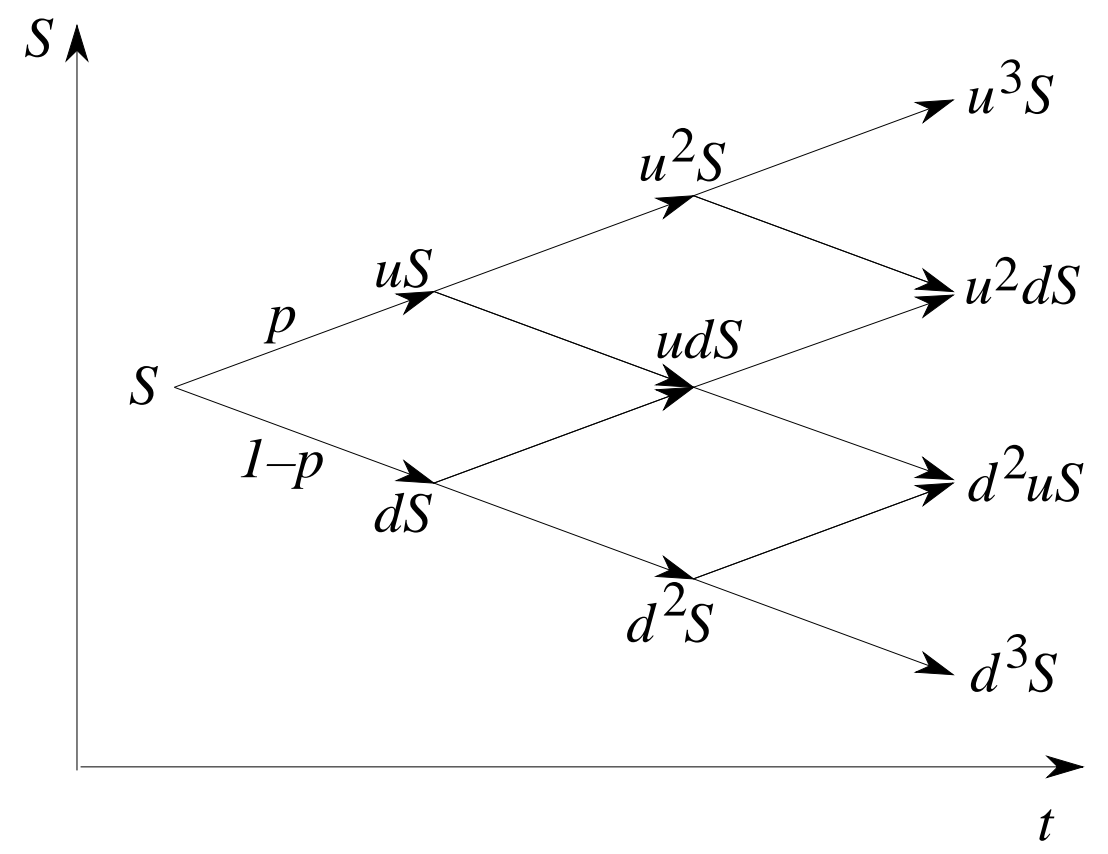

Figure 1: Binomial tree illustration for $n=3$

In the Cox, Ross, and Rubinstein (1979) binomial method, the stock price parameters are set to $u=e^{\sigma \sqrt{\Delta t}}, d=1 / u$, where $\Delta t=T / n$, and $n$ is the number of time steps between time 0 and $T$. The probability of an upmove is set to $p=\left(e^{r \Delta t}-d\right) /(u-d)$. With these choices, the binomial process converges to the geometric Brownian motion model as $n \rightarrow \infty$. The choice of $u d=1$ is not only convenient, but it reduces the number of numerical computations required. Other binomial variants use slightly different values for these parameters.

The dynamic programming routine is initialized by setting the call option price to $C_{T}\left(S_{T}\right)=\left(S_{T}-K\right)^{+}$at each of the terminal nodes. For example, at the top-right node in Figure $1, C_{T}\left(u^{3} S\right)$ is set to $\left(u^{3} S-K\right)^{+}$. At the previous node corresponding to stock price $u^{2} S$ at time $T-\Delta t$, the call option value $C_{T-\Delta t}\left(u^{2} S\right)$ is set to

$$
\max \left\{\left(u^{2} S-K\right)^{+}, e^{-r \Delta t}\left(p C_{T}\left(u^{3} S\right)+(1-p) C_{T}\left(u^{2} d S\right)\right)\right\} .
$$

That is, the American call value is the maximum of the immediate exercise value and the present value of continuing. The call values at the remaining nodes are determined in a similar recursive fashion. 
Figure 2 shows the binomial price as a function of the number of time steps. ${ }^{6}$ The well-known "oscillatory convergence" of the binomial method is evident in the figure. This has led many practitioners to use a variation of the binomial method where the $n$ - and $(n+1)$-step binomial prices are averaged. We term this the "binomial average" method.

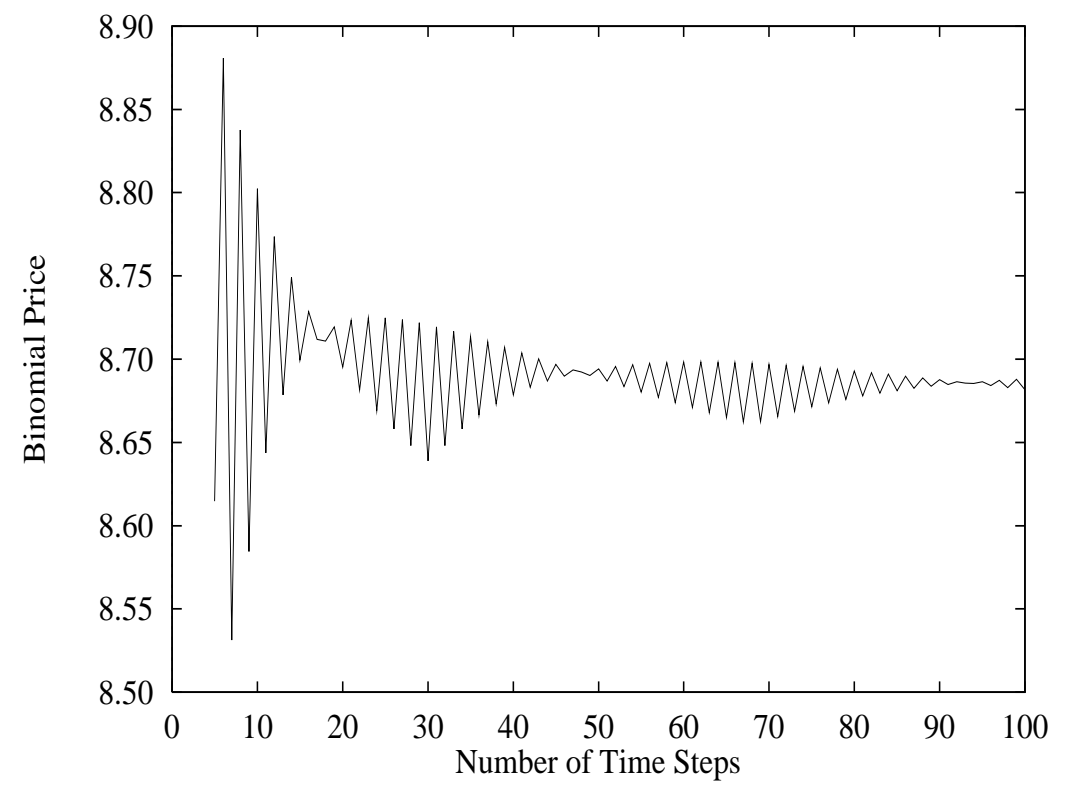

Figure 2: Binomial price versus number of time steps

Broadie and Detemple (1995b) suggest two modifications to the binomial method. In the first modification, the Black-Scholes formula replaces the usual "continuation value" at the time step just before option maturity. This method is termed BBS (for binomial with a $B$ lack-Scholes modification). Figure 3 shows the BBS price as a function of the number of time steps. Notice that the error is substantially reduced for the same number of time steps and the convergence to the true value is smoother. The smoother convergence suggests that Richardson extrapolation may be useful. The second modification adds Richardson extrapolation to the BBS method, and we refer to it as the BBSR method. In particular, the BBSR method with $n$ steps computes the BBS prices corresponding to $m=n / 2$ steps (say $C_{m}$ ) and $n$ steps ( say $C_{n}$ ) and then sets the BBSR price to $C=2 C_{n}-C_{m}$.

\subsection{LBA and LUBA Methods}

Broadie and Detemple (1995b) propose two approximation methods based on lower and upper bounds for the American option price. The lower bound is based on easily computable "capped call" option values. ${ }^{7}$ Then capped call option values are used in a different way to generate an approximation to the optimal exercise boundary. Unlike other pricing procedures, this approximate boundary (which is shown to lie uniformly below the optimal boundary) can be computed without recursion. An upper bound is then derived by substituting this approximate boundary in the integral equation (2.9).

\footnotetext{
${ }^{6}$ The parameters for this American call option are $S=105, K=100, r=0.05, \delta=0.02, \sigma=0.30$, and $T=0.2$. The true value of this option is 8.679 .

${ }^{7}$ See Broadie and Detemple (1995a) for a discussion of capped call options.
} 


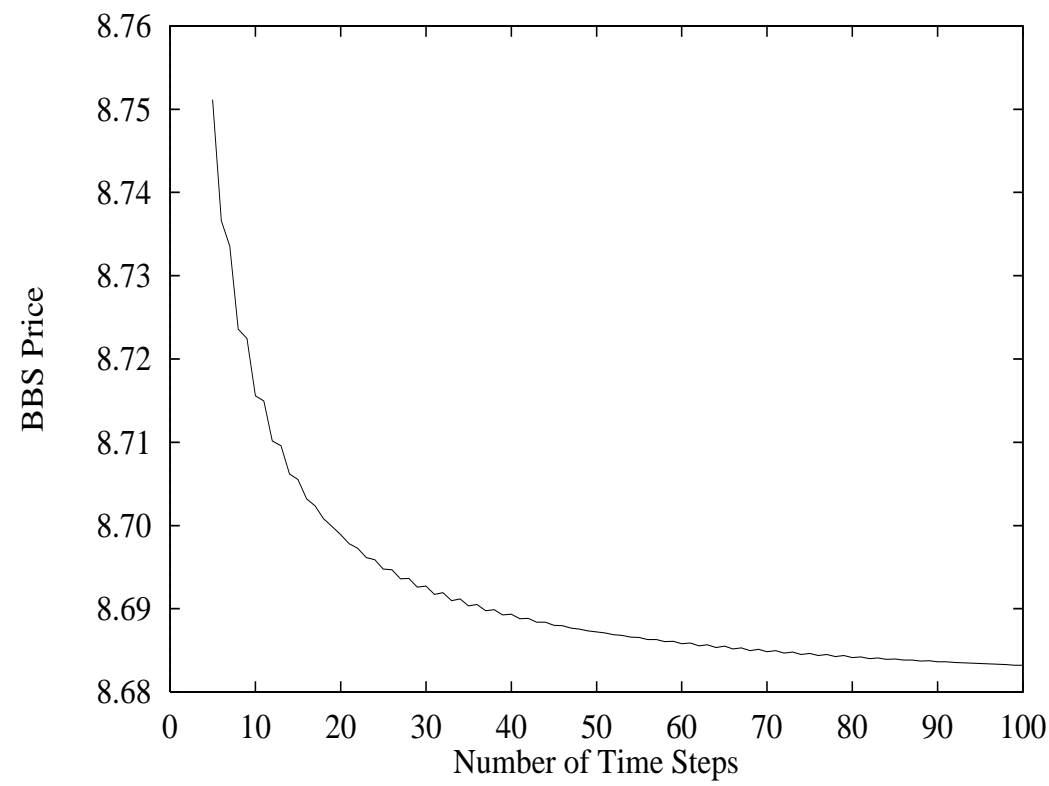

Figure 3: BBS price versus number of time steps

The payoff of a capped call option with cap $L$ is

$$
\left(\min \left(S_{t}, L\right)-K\right)^{+}
$$

if it is exercised at time $t \leq T$. Under the policy "exercise at the cap," the current value of the capped option, denoted $C_{0}\left(S_{0}, L\right)$, can be written explicitly (in terms of univariate cumulative normals). Since the "exercise at the cap" policy is a feasible but suboptimal strategy for the American option, $C_{0}\left(S_{0}, L\right)$ provides a simple lower bound on the American option price $C\left(S_{0}\right){ }^{8}$ A good lower bound is given by solving the univariate optimization problem:

$$
\max _{L \geq S_{0}} C_{0}\left(S_{0}, L\right)
$$

The lower bound approximation, LBA, is given by multiplying the lower bound by a weight $\lambda \geq 1$.

The optimal exercise boundary can be approximated by the following procedure. Define the derivative of the capped call option value with respect to the constant cap $L$, evaluated as $S_{t}$ approaches $L$ from below:

$$
D(L, t) \equiv \lim _{S_{t} \uparrow L} \frac{\partial C_{t}\left(S_{t}, L\right)}{\partial L} .
$$

An explicit formula for $D(L, t)$ is available. Define $L_{t}^{*}$ to be the solution to

$$
D(L, t)=0 .
$$

Note that this equation does not have to be solved recursively and it can be solved very fast for any given $t$. The function $L_{t}^{*}$ lies below the optimal exercise boundary $B_{t}$ for

\footnotetext{
${ }^{8}$ Similar ideas were independently proposed in Omberg (1987) and Bjerksund and Stensland (1992). We thank D. Lamberton for pointing out the latter reference to us.
} 
all $t \in[0, T]$. Using $L_{t}^{*}$ in place of $B$ in equation (2.9) leads to an upper bound for the American option value. LUBA, the lower and upper bound approximation, is a convex combination of these lower and upper bounds. Details are given in Broadie and Detemple (1995b).

\subsection{Performance Results}

To compare the performance of different methods, we follow the procedure in Broadie and Detemple (1995b). We first choose a large test set of options by randomly selecting parameters from a pre-determined distribution which is of practical interest. ${ }^{9}$ Then for each method we price the test set of options and compute speed and error measures. Speed is measured by the number of option prices computed per second. ${ }^{10}$ Two error measures are computed. First, root-mean-squared (RMS) relative error is defined by:

$$
\mathrm{RMS}=\sqrt{\frac{1}{m} \sum_{i=1}^{m} e_{i}^{2}}
$$

where $e_{i}=\left|\hat{C}_{i}-C_{i}\right| / C_{i}$ is the absolute relative error, $C_{i}$ is the "true" American option value (estimated by a 15,000-step binomial tree), $\hat{C}_{i}$ is the estimated option value, and the index $i$ refers to the $i^{\text {th }}$ option in the test set. To make relative error meaningful, the summation is taken over options in the dataset satisfying $C_{i} \geq 0.50$. Out of a sample of 5,000 options, $m=4,592$ satisfied this criterion. Second, the "maximum" relative error is defined to be observation $e_{i}$ such that $99.5 \%$ of the sample observations are below $e_{i}$. We do not take the largest observation, because estimating the maximum of a distribution is very difficult. ${ }^{11}$

We test the binomial method with the original Cox, Ross, and Rubinstein (1979) parameters (Binom CRR) and with the parameters suggested in Hull and White (1988, footnote 4) modified to account for dividends (Binom HW). We also test the "binomial average" method, the BBSR method, and the LBA and LUBA methods. The speed versus RMSerror results are shown in Figure $4 .{ }^{12}$ The binomial CRR and HW methods perform almost identically. For 200 time steps, their RMS-error is about $0.1 \%$, or about one cent on a $\$ 10$ option. This confirms the result in the folklore that using 200 binomial time steps produces "penny accuracy." The binomial average method performs insignificantly better than the standard binomial method. Apparently, the gain in accuracy is just about offset by the doubling of the work to compute prices at $n$ and $n+1$ time steps. The BBSR method performs significantly better than the other binomial methods in this speed-error tradeoff. Better still are the LBA and LUBA methods. The LUBA method has an RMS-error of about $0.02 \%$ (less than a 1000-step binomial tree) and a speed of over 1000 options per second (faster than a 50-step binomial tree).

The computational effort (work) with the standard binomial method increases as $O\left(n^{2}\right)$. Figure 4 shows the interesting result that RMS-error decreases approximately linearly with the number of time steps. Hence, the binomial error decreases as $O(1 / \sqrt{\text { work }}){ }^{13}$ Leisen

\footnotetext{
${ }^{9}$ The distribution of parameters for the test is: $\sigma$ is distributed uniformly between 0.1 and 0.6 ; $T$ is, with probability 0.75 , uniform between 0.1 and 1.0 years and, with probability 0.25 , uniform between 1.0 and 5.0 years; $K=100, S_{0}$ is uniform between 70 and $130 ; \delta$ is uniform between 0.0 and $0.10 ; r$ is, with probability 0.8 , uniform between 0.0 and 0.10 and, with probability 0.2 , equal to 0.0 . Finally, each parameter is selected independently of the others. Note that relative errors do not change if $S_{0}$ and $K$ are scaled by the same factor, i.e., only the ratio $S_{0} / K$ is of interest.

${ }^{10}$ The computations were done on a PC with a $133-\mathrm{MHz}$ Pentium processor.

${ }^{11} \mathrm{We}$ found that the sample maximum varies so widely within subsamples as to be an unreliable tool for comparing various methods. Results using the 99.5 percentile of the observations seem to be much less sensitive to the random test set used.

${ }^{12}$ Numbers next to each method indicate the number of time steps.

${ }^{13}$ This is also the convergence rate typically associated with simulation methods!
} 


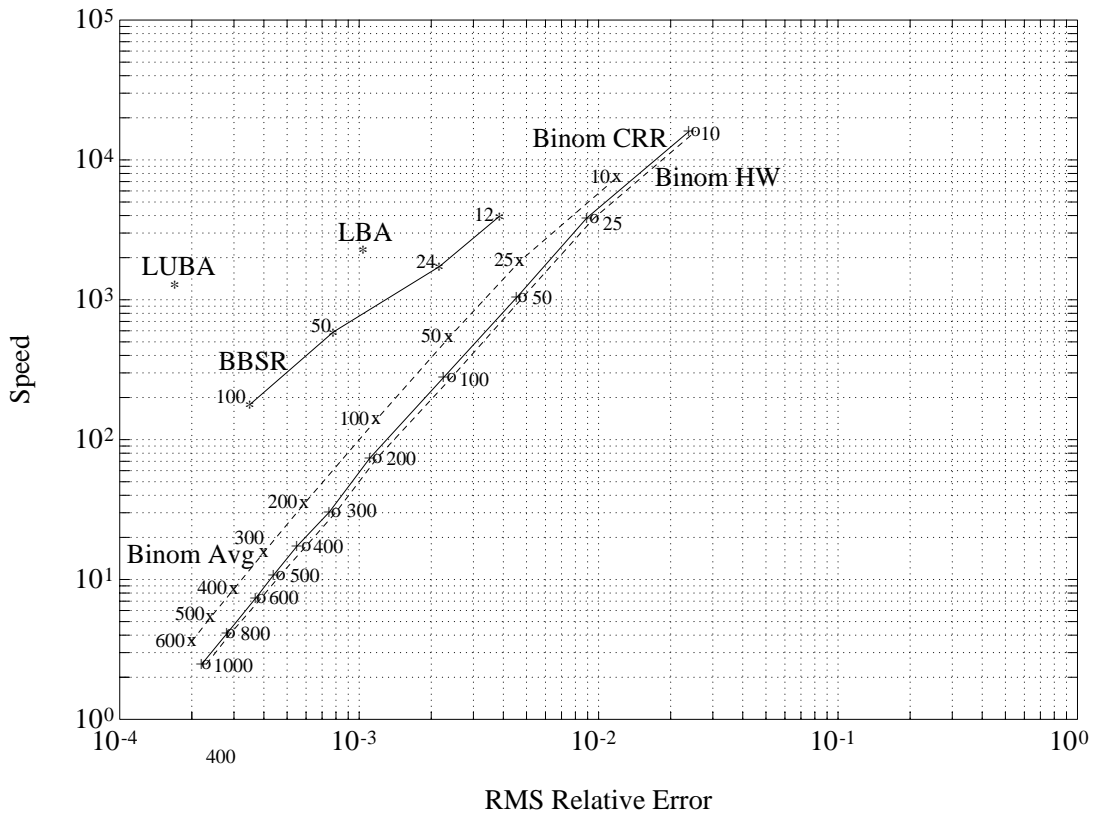

Figure 4: Speed versus RMS Relative Error

and Reimer (1995) show analytically that the binomial method has order one (i.e., linear) convergence for European options. ${ }^{14}$ They also suggest an interesting modification of the binomial method which appears to have order two convergence for European options and order one convergence (with a smaller constant) for American options.

Figure 5 shows the tradeoff between computation speed and the maximum error (recall that the "maximum" error is defined as the 99.5 percentile of the ordered absolute relative errors). The ranking of the methods is the same, however, the maximum error is approximately five times larger than the RMS-error for each method.

Comparative results of several other methods are given in Broadie and Detemple (1995b). Of the other methods tested, only the method of lines of Carr and Faguet (1995) has an RMS-error of $0.1 \%$ or less. AitSahlia (1995) and AitSahlia and Lai (1996) describe a pricing method for American options which uses a continuity correction technique for estimating the optimal exercise boundary. Their method also appears to be very promising. ${ }^{15}$ Recent methods represent orders of magnitude improvement over earlier approaches in terms of speed and/or accuracy. The BBSR method is a simple modification of the binomial method which is simple to program and performs very well. The LUBA method is the only method tested which also provides upper and lower bounds. The binomial method is very easy to program and the algorithm can easily be adapted to many alternative contract specifications. All of the methods tested can generate prices as well as price derivatives. Finally, the storage requirements of the tested methods are minimal.

The determination of a closed-form solution for the optimal stopping boundary and the corresponding American option price remains an open question. However, we conclude from these recent results that from a numerical viewpoint, the single asset American option pricing problem in the standard model is essentially solved. Many challenges remain for the pricing of path-dependent options, multi-asset options, interest-rate sensitive securities,

\footnotetext{
${ }^{14}$ They also show that the same order of convergence holds for the parameters used in the Cox, Ross, and Rubinstein (1979), Jarrow and Rudd (1983), and Tian (1993) binomial variants.

${ }^{15}$ It was not tested because it has not yet been extended to handle dividends.
} 


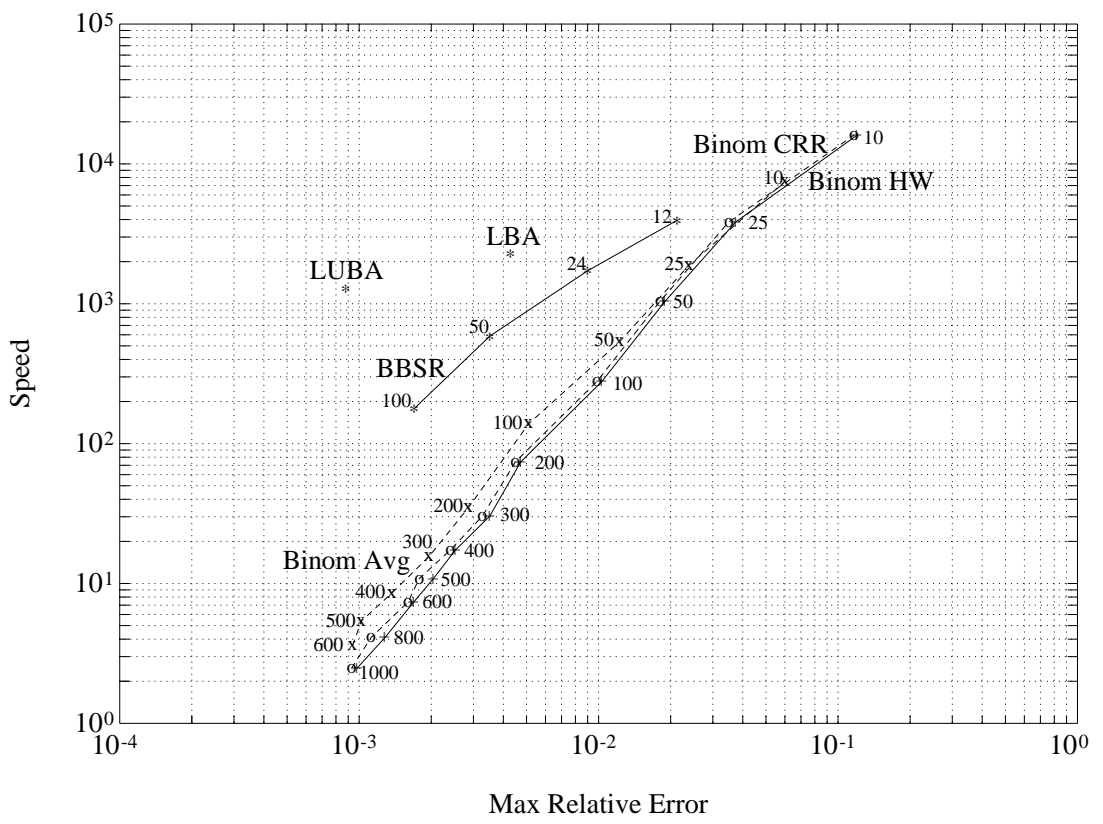

Figure 5: Speed versus Max Relative Error

and options in more general models (e.g., nonconstant volatility). Some of these issues are explored briefly in the next two sections.

\section{Barrier and Lookback Options}

Capped call options are one example of barrier options - options whose payoff depends on the value of the underlying asset relative to a barrier level. Knock-in options are another example. These options have a zero payoff, unless the underlying asset price crosses a pre-determined barrier which makes the option come "alive." Barrier options are treated in Rubinstein and Reiner (1991) and Rich (1994). For an overview of these and other types of exotic options, see Jarrow (1995) and Nelken (1995).

Cox and Rubinstein (1985) describe a straightforward modification of the binomial method for pricing certain barrier options. Broadie and Detemple (1993) and Boyle and Lau (1994) first pointed out the slow convergence of the binomial method for pricing barrier options. For a comparable number of time steps, the binomial pricing error for barrier options can be two orders of magnitude larger than for standard options.

Boyle and Lau (1994) identify the cause of the problem and suggest a remarkably simple and effective solution. As the number of time steps in the binomial method changes, the placement of the barrier relative to the layers of nodes of the tree changes. They recommend choosing the number of time steps $n$ so that there is a layer of nodes at or just beyond the barrier. These "good values" of $n$ can easily be determined in advance of the pricing computation. Their results show that these choices for $n$ restore the original error properties of the binomial method.

Numerical pricing of barrier options is also studied in Derman, Kani, Ergener, and Bardhan (1995), and in Ritchken (1995). Derman et al. (1995) suggest an interpolation scheme for improving the pricing error of lattice methods applied to barrier options. This approach is especially useful when the volatility of the underlying asset is not constant. Ritchken 
(1995) suggests using a trinomial procedure, where the trinomial "stretch" parameter is chosen so that the barrier coincides with a layer of nodes.

The payoff of a lookback call option is $\left(S_{T}-\min _{0 \leq t \leq T} S_{t}\right)$ and a lookback put is $\left(\max _{0<t<T} S_{t}-S_{T}\right)$. Analytical solutions have been given for European versions of these options in the standard model (see, e.g., Goldman, Sosin, and Gatto 1979 and Conze and Viswanathan 1991). Numerical techniques must be used for American lookbacks, to handle discrete dividends, when volatility is not constant, or for other variations of the standard model. The standard binomial approach does not apply to the case of lookbacks because of the path-dependent payoff.

Babbs (1992) and Cheuk and Vorst (1994) suggest a clever change of numeraire so that a version of the binomial method is again applicable. Hull and White (1993) resolve the path dependency by the standard technique of adding an additional state variable. This adds an extra dimension to the binomial method, which considerably increases its computation time. The resulting method, however, is very flexible. Kat (1995) offers a summary and comparison of these approaches.

For many path-dependent option contracts, the payoff does not depend on the continuous price path, but rather it depends on the price of the underlying asset at discrete points in time. For barrier options, it is often the case that the barrier-crossing event can only be triggered at specific dates or times. For lookback options, the maximum or minimum price might be determined at daily closings, for example. The implications of ignoring the difference between continuous and discrete monitoring is discussed in Flesaker (1992), Chance (1994), and Kat and Verdonk (1995). Numerical methods and analytical approximations for discrete path-dependent options are given in Broadie, Glasserman, and Kou (1995, 1996) and Levy and Mantion (1995).

\section{Methods for Multiple State Variables}

Options on multiple assets ("rainbow options") are being traded with increasing frequency. For example, in 1994 the New York Mercantile Exchange began trading options on crack spreads (e.g., the difference between unleaded gasoline and crude oil futures prices, or the difference between heating oil and crude oil futures prices). Other examples include options on the maximum of two or more asset prices, dual-strike options, and portfolio or basket options. ${ }^{16}$

In the multi-asset context, the standard model is a straightforward generalization of (2.1):

$$
d S_{t}^{i}=S_{t}^{i}\left[\left(\mu_{i}-\delta_{i}\right) d t+\sigma_{i} d W_{t}^{i}\right]
$$

where $S_{t}^{i}$ is the price of asset $i$ at time $t$ and where the $W^{i}$ are standard Brownian motion processes $(i=1, \ldots, n)$ and the correlation between $W^{i}$ and $W^{j}$ is $\rho_{i j}$. With a constant rate of interest $r$, the risk-neutral form of (4.1) is given by replacing each $\mu_{i}$ by $r$.

Multinomial approaches to pricing options with two or more state variables are given in Boyle (1988), Boyle, Evnine, and Gibbs (1989), Madan, Milne, and Shefrin (1989), Cheyette (1990), He (1990), Kamrad and Ritchken (1991), and Rubinstein (1994). The basic idea of the multinomial approaches is the same as in the single asset case, namely, to discretize the risk-neutral process specified in equation (4.1) and then to use dynamic programming to solve for the option price. A tree with four branches per node in the two-asset case is illustrated in Figure 6.

Boyle, Evnine, and Gibbs (1989), hereafter BEG, proposed a general lattice method to price contingent claims on $k$ assets. The BEG method has four branches per node in

\footnotetext{
${ }^{16}$ Closed-form solutions for some European multi-asset options are given in Boyle (1993). Properties of American option prices and optimal exercise boundaries are investigated in Broadie and Detemple (1995c) in the multi-asset context.
} 


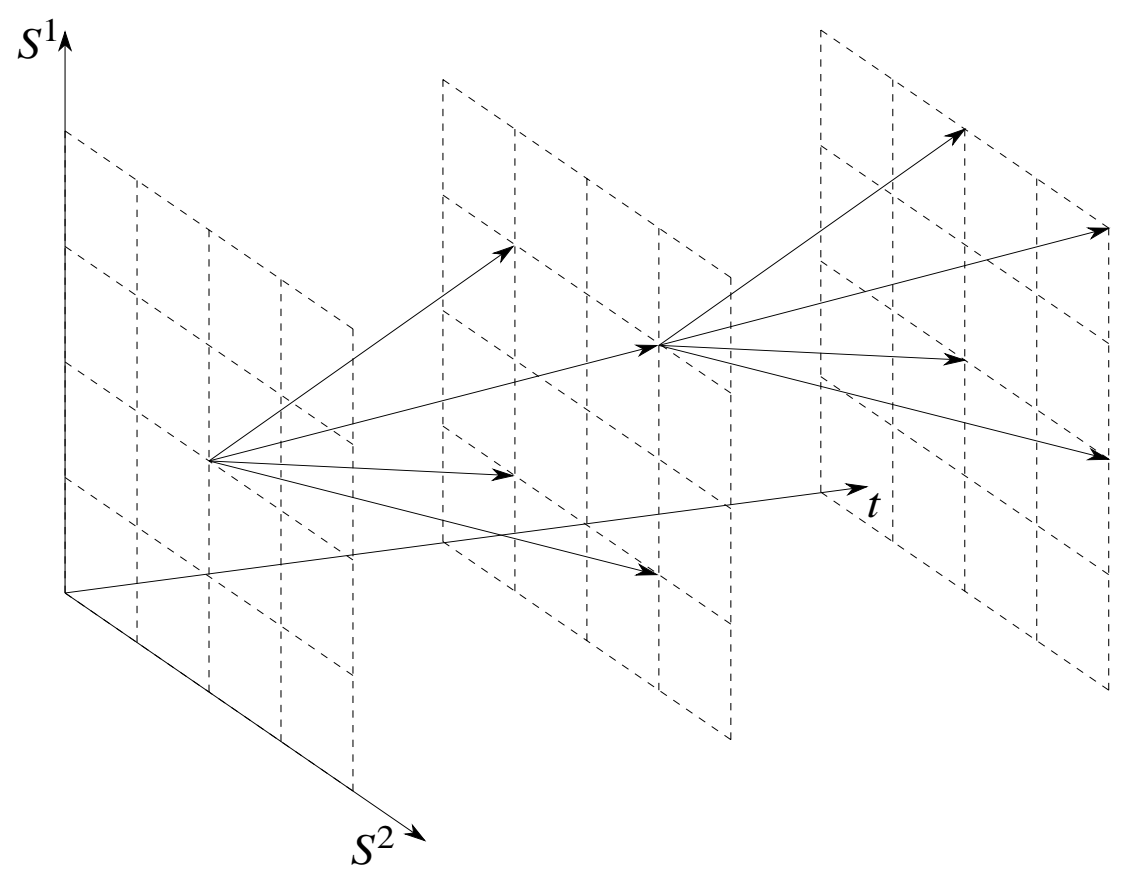

Figure 6: Evolution of a two-dimensional binomial tree (4-branch method)

the two-asset case, and $2^{k}$ branches per node in the $k$-asset case. For the two-asset case, the node $\left(S^{1}, S^{2}\right)$ is connected to $\left(u_{1} S^{1}, u_{2} S^{2}\right)$ with probability $p_{u u}$, to $\left(u_{1} S^{1}, d_{2} S^{2}\right)$ with probability $p_{u d}$, to $\left(d_{1} S^{1}, u_{2} S^{2}\right)$ with probability $p_{d u}$, and to $\left(d_{1} S^{1}, d_{2} S^{2}\right)$ with probability $p_{d d}$. As in the single-asset case, $u_{i}=e^{\sigma_{i} \sqrt{\Delta t}}$ and $d_{i}=1 / u_{i}$ for $i=1,2$. The transition probabilities are defined by

$$
\begin{aligned}
& p_{u u}=\frac{1}{4}\left(1+\rho+\sqrt{\Delta t}\left(\frac{\nu_{1}}{\sigma_{1}}+\frac{\nu_{2}}{\sigma_{2}}\right)\right) \\
& p_{u d}=\frac{1}{4}\left(1-\rho+\sqrt{\Delta t}\left(\frac{\nu_{1}}{\sigma_{1}}-\frac{\nu_{2}}{\sigma_{2}}\right)\right) \\
& p_{d u}=\frac{1}{4}\left(1-\rho+\sqrt{\Delta t}\left(-\frac{\nu_{1}}{\sigma_{1}}+\frac{\nu_{2}}{\sigma_{2}}\right)\right) \\
& p_{d d}=\frac{1}{4}\left(1+\rho-\sqrt{\Delta t}\left(\frac{\nu_{1}}{\sigma_{1}}+\frac{\nu_{2}}{\sigma_{2}}\right)\right),
\end{aligned}
$$

where $\nu_{i}=r-\delta_{i}-\frac{1}{2} \sigma_{i}^{2}$, for $i=1,2$, and $\rho=\rho_{12}$. For the test results which follow, we refer to this BEG approach as the "4-Branch" method.

Boyle (1988) proposed a lattice method in the two-asset case which has five branches per node, where the additional branch represents a horizontal move, i.e., a transition from $\left(S^{1}, S^{2}\right)$ to the same node $\left(S^{1}, S^{2}\right)$ one time-period later. Kamrad and Ritchken (1991) proposed a general lattice method for $k$ assets. In the case of two assets, their method has five branches per node. Like the trinomial method in the single asset case, their method has an additional "stretch" parameter, denoted $\lambda$. When $\lambda=1$, the Kamrad and Ritchken method reduces to the BEG method. In the two asset case, Kamrad and Ritchken recommend using $\lambda=1.11803$, and for the test results which follow, we refer to this as the "5-Branch" method.

To compare the performance of the 4-Branch and the 5-Branch methods, we price 
European max-options on two assets. The payoff of the max-option is $\left(\max \left(S_{T}^{1}, S_{T}^{2}\right)-K\right)^{+}$. We test the methods in the European case because the true price can be determined by the analytical formula given in Johnson $(1981,1987)$ and Stulz (1982). We chose a test set of 5,000 options by randomly selecting parameters from a pre-determined distribution. ${ }^{17}$ Then for each method we price the test set of options and compute the usual speed and RMS-error measures. The results are shown in Figure $7 .{ }^{18}$

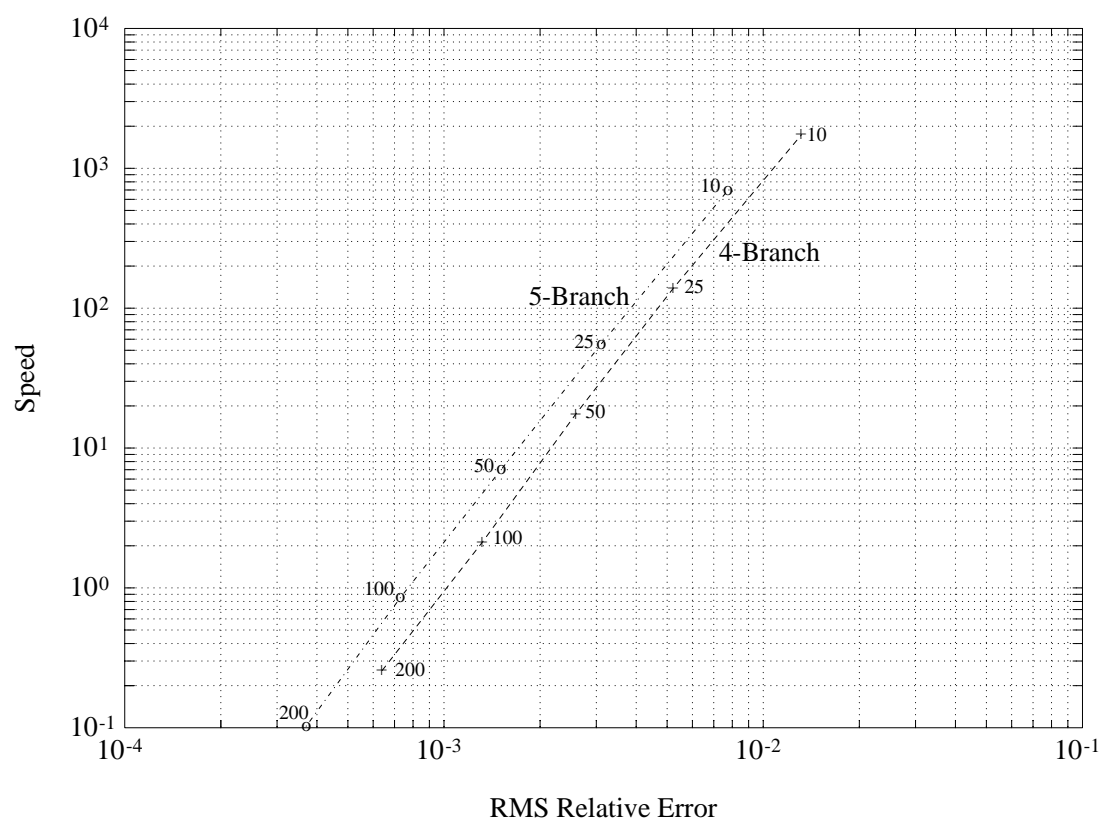

Figure 7: Speed versus RMS Relative Error for European Call Options on the Maximum of Two Assets

For both methods, Figure 7 shows that the RMS-error decreases approximately linearly with the number of time steps. The RMS-error in the two-asset case is comparable to the single-asset case with the same number of time steps. ${ }^{19}$ However, the computational effort with both two-asset methods increases as $O\left(n^{3}\right)$. With current computing technology, these lattice methods are practical for problems of at most three or four dimensions. For higher dimensions, the computation time and the memory/storage requirements become prohibitive.

\subsection{Simulation Methods}

To overcome the "curse of dimensionality" of current lattice methods, recent work has focused on simulation-based approaches. The convergence rate of Monte Carlo simulation methods is typically independent of the number of state variables, and so this approach

\footnotetext{
${ }^{17}$ The distribution of parameters for the test is: $\sigma_{i}$ is distributed uniformly between 0.1 and $0.6 ; T$ is, with probability 0.75 , uniform between 0.1 and 1.0 years and, with probability 0.25 , uniform between 1.0 and 5.0 years; $K=100, S_{0}^{i}$ is uniform between 70 and $130 ; \delta_{i}$ is uniform between 0.0 and $0.10 ; r$ is, with probability 0.8 , uniform between 0.0 and 0.10 and, with probability 0.2 , equal to $0.0, \rho$ follows a triangular distribution between -1 and $1(i=1,2$, where applicable). Finally, each parameter is selected independently of the others.

${ }^{18}$ Numbers next to each method indicate the number of time steps.

${ }^{19}$ This two-asset test if for the easier European option case, while the single-asset test was for American options.
} 
should be increasingly attractive as the dimension of the problem grows. The simulation approach was introduced to finance in Boyle (1997). For a recent survey see Boyle, Broadie, and Glasserman (1995).

While the simulation approach has been used extensively to price European-style contingent claims, only recently have there been attempts to extend the method to price American-style claims. The first attempt to price American options using simulation is given in Tilley (1993). This effort created considerable interest by demonstrating the potential practicality of using simulation in this context. More recent developments are given in Barraquand and Martineau (1995) and Broadie and Glasserman (1995). 


\section{$5 \quad$ References}

Abramowitz, W. \& Stegun, I. (1972) Handbook of Mathematical Functions, Dover Publications, New York.

AitSahlia, F. (1995) 'Optimal Stopping and Weak Convergence Methods for Some Problems in Financial Economics', Ph.D. dissertation, Stanford University.

AitSahlia, F. \& Lai, T. (1996) 'Approximations for American Options', working paper, Cornell University.

Amin, K. (1991) 'On the Computation of Continuous Time Option Prices Using Discrete Approximations', Journal of Financial and Quantitative Analysis 26, 477-496.

Amin, K. \& Khanna, A. (1994) 'Convergence of American Option Values from Discreteto Continuous-Time Financial Models', Mathematical Finance 4, 289-304.

Amin, K. (1995) 'Option Pricing Trees', Journal of Derivatives 2, No. 4, 34-46.

Amin, K. \& Bodurtha, J. (1995) 'Discrete-Time American Option Valuation with Stochastic Interest Rates', Review of Financial Studies 8, 193-234.

Babbs, S. (1992) 'Binomial Valuation of Lookback Options', working paper, Midland Global Markets, London, England.

Barone-Adesi, G. \& Whaley, R. (1987) 'Efficient Analytical Approximation of American Option Values', Journal of Finance 42, 301-320.

Barraquand, J. \& Martineau, D. (1995) 'Numerical Valuation of High Dimensional Multivariate American Securities', Journal of Financial and Quantitative Analysis 30, 383405.

Bensoussan, A. (1984) 'On the Theory of Option Pricing', Acta Applicandae Mathematicae 2, 139-158.

Bjerksund, P. \& Stensland, G. (1992) 'Closed Form Approximation of American Option Prices', working paper, Norwegian School of Economics and Business Administration, Bergen, Norway, to appear in the Scandinavian Journal of Management.

Black, F. \& Scholes, M. (1973) 'The Pricing of Options and Corporate Liabilities', Journal of Political Economy 81, 637-654.

Blomeyer, E. (1986) 'An Analytic Approximation for the American Put Price for Options on Stocks with Dividends', Journal of Financial and Quantitative Analysis 21, 229-233.

Boyle, P. (1977) 'Options: A Monte Carlo Approach', Journal of Financial Economics 4, 323-338.

Boyle, P. (1988) 'A Lattice Framework for Option Pricing with Two State Variables', Journal of Financial and Quantitative Analysis 23, 1-12.

Boyle, P. (1993) 'New Life Forms on the Options Landscape', Journal of Financial Engineering 2, 217-252.

Boyle, P., Evnine, J., \& Gibbs, S. (1989) 'Numerical Evaluation of Multivariate Contingent Claims', Review of Financial Studies 2, 241-250.

Boyle, P. \& Lau, S. (1994) 'Bumping Up Against the Barrier with the Binomial Method', Journal of Derivatives 1, No. 4, 6-14. 
Boyle, P., Broadie, M., \& Glasserman, P. (1995) 'Monte Carlo Methods for Security Pricing', working paper, Columbia University, to appear in the Journal of Economic Dynamics and Control.

Breen, R. (1991) 'The Accelerated Binomial Option Pricing Model', Journal of Financial and Quantitative Analysis 26, 153-164.

Brennan, M. \& Schwartz, E. (1977) 'The Valuation of American Put Options', Journal of Finance 32, 449-462.

Brennan, M. \& Schwartz, E. (1978) 'Finite Difference Methods and Jump Processes Arising in the Pricing of Contingent Claims: A Synthesis', Journal of Financial and Quantitative Analysis 13, 461-474.

Broadie, M. \& Detemple, J. (1993) 'The Valuation of American Capped Call Options', working paper, Columbia University.

Broadie, M. \& Detemple, J. (1995a) 'American Capped Call Options on Dividend Paying Assets', Review of Financial Studies 8, 161-191.

Broadie, M. \& Detemple, J. (1995b) 'American Option Valuation: New Bounds, Approximations, and a Comparison of Existing Methods', working paper, Columbia University, to appear in the Review of Financial Studies.

Broadie, M. \& Detemple, J. (1995c) 'The Valuation of American Options on Multiple Assets', working paper, Columbia University, to appear in Mathematical Finance.

Broadie, M. \& Glasserman, P. (1995) 'Pricing American-Style Securities Using Simulation', working paper, Columbia University, under review at Journal of Economic Dynamics and Control.

Broadie, M., Glasserman, P., \& Kou, S. (1995) 'A Continuity Correction for Discrete Barrier Options', working paper, Columbia University, under review at Mathematical Finance.

Broadie, M., Glasserman, P., \& Kou, S. (1996) 'Connecting Discrete and Continuous PathDependent Options', working paper, Columbia University.

Bunch, D. \& Johnson, H. (1992) 'A Simple and Numerically Efficient Valuation Method for American Puts Using a Modified Geske-Johnson Approach', Journal of Finance 47, 809-816.

Carr, P. \& Faguet, D. (1995) 'Fast Accurate Valuation of American Options', working paper, Cornell University.

Carr, P., Jarrow, R., \& Myneni, R. (1992) 'Alternative Characterizations of American Put Options', Mathematical Finance 2, 87-106.

Chance, D. (1994) 'The Pricing and Hedging of Limited Exercise Caps and Spreads', Journal of Financial Research 17, 561-584.

Chesney, M. \& Gibson, R. (1995) 'State Space Symmetry and Two-Factor Option Pricing Models', Advances in Futures and Options Research 8, 85-112.

Cheuk, T. \& Vorst, T. (1994) 'Lookback Options and the Observation Freqeuncy', working paper, Erasmus Univerity, Rotterdam, The Netherlands.

Cheyette, O. (1990) 'Pricing Options on Multiple Assets', Advances in Futures and Options Research 4, 69-81.

Conze, A. \& Viswanathan, R. (1991) 'Path Dependent Options: The Case of Lookback Options', Journal of Finance 46, 1893-1907. 
Cottle, R., Pang, J.-S.,\& Stone, R. (1992) The Linear Complementarity Problem, Academic Press, Boston.

Courtadon, G. (1982) 'A More Accurate Finite Difference Approximation for the Valuation of Options', Journal of Financial and Quantitative Analysis 17, 697-705.

Cox, J. \& Ross, S. (1976) 'The Valuation of Options for Alternative Stochastic Processes', Journal of Financial Economics 3, 145-166.

Cox, J., Ross, S., \& Rubinstein, M. (1979) 'Option Pricing: A Simplified Approach', Journal of Financial Economics 7, 229-263.

Cox, J. \& Rubinstein, M. (1985) Options Markets, Prentice-Hall, Engelwood Cliffs, New Jersey.

Curran, M., (1995) 'Accelerating American Option Pricing in Lattices', Journal of Derivatives 3, No. 2, 8-17.

Dempster, M. (1994) 'Fast Numerical Valuation of American, Exotic and Complex Options', Department of Mathematics research report, University of Essex, Colchester, England.

Derman, E., Kani, I., Ergener, D., \& Bardhan, I. (1995) 'Enhanced Numerical Methods for Options with Barriers', Financial Analysts Journal 51, No. 6, 65-74.

El Karoui, N. \& Karatzas, I. (1991) 'A New Approach to the Skorohod Problem and its Applications', Stochastics and Stochastics Reports 34, 57-82.

Flesaker, B. (1992) 'The Design and Valuation of Capped Stock Index Options', working paper, Department of Finance, University of Illinois, Champaign, IL.

Geske, R. (1979) 'A Note on an Analytical Valuation Formula for Unprotected American Options on Stocks with Known Dividends', Journal of Financial Economics 7, 375-380.

Geske, R. \& Johnson, H. (1984) 'The American Put Options Valued Analytically', Journal of Finance 39, 1511-1524.

Geske, R. \& Shastri, K. (1985) 'Valuation by Approximation: A Comparison of Alternative Option Valuation Techniques', Journal of Financial and Quantitative Analysis 20, 4571.

Goldman, M., Sosin, H., \& Gatto, M. (1979) 'Path Dependent Options: Buy at the Low, Sell at the High', Journal of Finance 34, 1111-1127.

Harrison, M. \& Kreps, D. (1979) 'Martingales and Arbitrage in Multiperiod Security Markets', Journal of Economic Theory 20, 381-408.

Harrison, M. \& Pliska, S. (1981) 'Martingales and Stochastic Integrals in the Theory of Continuous Trading' Stochastic Processes and their Applications 11, 215-260.

He, H. (1990) 'Convergence from Discrete- to Continuous-Time Contingent Claim Prices', Review of Financial Studies 3, 523-546.

Ho, T.S., Stapleton, R., \& Subrahmanyam, M. (1994) 'A Simple Technique for the Valuation and Hedging of American Options', Journal of Derivatives 2, No. 1, 52-66.

Huang, J., Subrahmanyam, M., \& Yu, G. (1995) 'Pricing and Hedging American Options: A Recursive Integration Method', working paper, New York University, to appear in the Review of Financial Studies.

Hull, J. (1993) Options, Futures, and Other Derivative Securities, $2^{\text {nd }}$ edition, PrenticeHall, Englewood Cliffs, New Jersey.

Hull, J. \& White, A. (1988) 'The Use of the Control Variate Technique in Option Pricing', Journal of Financial and Quantitative Analysis 23, 237-251. 
Hull, J. \& White, A. (1990) 'Valuing Derivative Securities Using the Explicit Finite Difference Method', Journal of Financial and Quantitative Analysis 25, 87-100.

Hull, J. \& White, A. (1993) 'Efficient Procedures for Valuing European and American Path-Dependent Options', Journal of Derivatives 1, No. 1, 21-32.

Hull, J. \& White, A. (1994a) 'Numerical Procedures for Implementing Term Structure Models I: Single-Factor Models', Journal of Derivatives 2, No. 1, 7-16.

Hull, J. \& White, A. (1994b) 'Numerical Procedures for Implementing Term Structure Models II: Two-Factor Models', Journal of Derivatives 2, No. 2, 37-48.

Jacka, S. (1991) 'Optimal Stopping and the American Put', Mathematical Finance 1, 1-14.

Jaillet, P., Lamberton, D., \& Lapeyre, B. (1990) 'Variational Inequalities and the Pricing of American Options', Acta Applicandae Mathematicae 21, 263-289.

Jarrow, R., ed. (1995) Over the Rainbow, Risk Publications, London, England.

Jarrow, R. \& Rudd, A. (1983) Option Pricing, Dow Jones-Irwin, Homewood, Illinois.

Jarrow, R. \& Turnbull, S. (1996) Derivative Securities, South-Western Publishing, Cincinnati, Ohio.

Johnson, H. (1981) 'The Pricing of Complex Options', working paper, Louisiana State University.

Johnson, H. (1983) 'An Analytic Approximation for the American Put Price', Journal of Financial and Quantitative Analysis 18, 141-148.

Johnson, H. (1987) 'Options on the Maximum or the Minimum of Several Assets', Journal of Financial and Quantitative Analysis 22, 227-283.

Kamrad, B. \& Ritchken, P. (1991) 'Multinomial Approximating Models for Options with $k$ State Variables', Management Science 37, 1640-1652.

Karatzas, I. (1988) 'On the Pricing of American Options', Applied Mathematics and Optimization 17, 37-60.

Kat, H. (1995) 'Pricing Lookback Options Using Binomial Trees: An Evaluation', Journal of Financial Engineering 4, 375-398.

Kat, H. \& Verdonk, L. (1995) 'Tree Surgery', RISK 8, No. 2, 53-56.

Kim, I. (1990) 'The Analytic Valuation of American Options', Review of Financial Studies 3, 547-572.

Kim, I. (1994) 'Analytical Approximation of the Optimal Exercise Boundaries for American Futures Option', Journal of Futures Markets 14, 1-24.

Kim, I. \& Byun, S. (1994) 'Optimal Exercise Boundary in a Binomial Option Pricing Model', Journal of Financial Engineering 3, 137-158.

Lamberton, D. (1993) 'Convergence of the Critical Price in the Approximation of American Options', Mathematical Finance 3, 179-190.

Lamberton, D. (1995) 'Error Estimates for the Binomial Approximation of American Put Options', working paper, Université de Marne-la-Vallée, Noisy-le-Grand, France.

Leisen, D. \& Reimer, M. (1995) 'Binomial Models for Option Valuation - Examining and Improving Convergence', Working Paper B-309, University of Bonn.

Levy, E. \& Mantion, F. (1995) 'Approximate Valuation of Discrete Lookback Options', HSBC Midland, London, England. 
Li, A., Ritchken, P., \& Sankarasubramanian, L. (1995) 'Lattice Models for Pricing American Interest Rate Claims', Journal of Finance 50, 719-737.

MacMillan, L.W. (1986) 'An Analytic Approximation for the American Put Price', Advances in Futures and Options Research 1, 119-139.

Madan, D., Milne, F., \& Shefrin, H. (1989) 'The Multinomial Option Pricing Model and its Brownian and Poisson Limits', Review of Financial Studies 4, 251-266.

Marchuk, G. \& Shaidurov, V. (1983) Difference Methods and Their Extrapolations, Springer Verlag, New York.

McDonald, R. \& Schroder, M. (1990) 'A Parity Result for American Options', working paper, Northwestern University.

McKean, Jr., H. (1965) 'Appendix: A Free Boundary Problem for the Heat Equation Arising from a Problem in Mathematical Economics', Industrial Management Review 6, $32-39$.

Merton, R. (1973) 'Theory of Rational Option Pricing', Bell Journal of Economics and Management Science 4, 141-183.

Moro, B. (1995) 'Fast Computation of Cumulative Normal Distribution Function', working paper, TMG Financial Products, Greenwich, Connecticut; forthcoming in Risk.

Nelken, I., ed. (1995) The Handbook of Exotic Options, Dow Jones-Irwin, Homewood, Illinois.

Nelson, D. \& Ramaswamy, K. (1990) 'Simple Binomial Processes as Diffusion Approximations in Financial Models', Review of Financial Studies 3, 393-430.

Omberg, E. (1987) 'The Valuation of American Puts with Exponential Exercise Policies', Advances in Futures and Options Research 2, 117-142.

Omberg, E. (1988) 'Efficient Discrete Time Jump Process Models in Option Pricing', Journal of Financial and Quantitative Analysis 23, 161-174.

Parkinson, M. (1977) 'Option Pricing: The American Put', Journal of Business 50, 21-36.

Pelsser, A. \& Vorst, T. (1994) 'The Binomial Model and the Greeks', Journal of Derivatives 1, No. 3, 45-49.

Press, W., Teukolsky, S., Vetterling, W., \& Flannery, B. (1992) Numerical Recipes in C: The Art of Scientific Computing, $2^{\text {nd }}$ edition, Cambridge University Press, Cambridge.

Rendleman, R. \& Bartter, B. (1979) 'Two-State Option Pricing', Journal of Finance 34, 1093-1110.

Rich, D. (1994) 'The Mathematical Foundations of Barrier Option Pricing Theory', $A d-$ vances in Futures and Options Research 7, 267-312.

Ritchken, P. (1995) 'On Pricing Barrier Options', Journal of Derivatives 3, No. 2, 19-28.

Roll, R. (1977) 'An Analytic Valuation Formula for Unprotected American Call Options on Stocks with Known Dividends', Journal of Financial Economics 5, 251-258.

Rubinstein, M. (1994) 'Return to Oz', Risk 7, No. 11, 67-71.

Rubinstein, M. \& Reiner, E. (1991) 'Breaking Down the Barriers', RISK 4, (September) $28-35$.

Schwartz, E. (1977) 'The Valuation of Warrants: Implementing a New Approach', Journal of Financial Economics 4, 79-93.

Stoll, H. \& Whaley, R. (1993) Futures and Options: Theory and Applications, SouthWestern Publishing, Cincinnati, Ohio. 
Stulz, R. (1982) 'Options on the Minimum or the Maximum of Two Risky Assets', Journal of Financial Economics 10, 161-185.

Tian, Y. (1992) 'A Simplified Binomial Approach to the Pricing of Interest-Rate Contingent Claims', Journal of Financial Engineering 1, 14-37.

Tian, Y. (1993) 'A Modified Lattice Approach to Option Pricing', Journal of Futures Markets 13, 563-577.

Tian, Y. (1994) 'A Reexamination of Lattice Procedures for Interest Rate-Contingent Claims', Advances in Futures and Options Research 7, 87-111.

Tilley, J. (1993) 'Valuing American Options in a Path Simulation Model', Transactions of the Society of Actuaries 45, 83-104.

Trigeorgis, L. (1991) 'A Log-Transformed Binomial Numerical Analysis Method for Valuing Complex Multi-Option Investments', Journal of Financial and Quantitative Analysis 26, 309-326.

Whaley, R.E. (1981) 'On the Valuation of American Call Options on Stocks with Known Dividends', Journal of Financial Economics 9, 207-211.

Wilmott, P., Dewynne, J., \& Howison, S. (1993) Option Pricing: Mathematical Models and Computation, Oxford Financial Press, Oxford, England.

Zhang, X. (1995) 'Numerical Analysis of American Option Pricing in a Jump-Diffusion Model', working paper, Société Générale, Paris-La Défense, France. 


\section{Liste des publications au CIRANO *}

Série Scientifique / Scientific Series (ISSN 1198-8177)

96s-14 Numerical Methods for Pricing Derivative Securities / Mark Broadie et Jérôme Detemple

96s-13 Monitoring New Technological Developments in the Electricity Industry : An International Perspective / Louis A. Lefebvre, Élisabeth Lefebvre et Lise Préfontaine

96s-12 Model Error in Contingent Claim Models Dynamic Evaluation / Eric Jacquier et Robert Jarrow

96s-11 Mesures de la croissance de la productivité dans un cadre d'équilibre général : L'Économie du Québec entre 1978 et 1984 / Pierre Mohnen, Thijs ten Raa et Gilles Bourque

96s-10 The Efficiency of Collective Bargaining in Public Schools / Daniel S. Hosken et David N. Margolis

96s-09 Constant Consumption and the Economic Depreciation of Natural Capital : The NonAutonomous Case / John M. Hartwick et Ngo Van Long

96s-08 Upstream-Downstream Specialization by Integrated Firms in a Partially Integrated Industry / Gérard Gaudet, Ngo Van Long et Antoine Soubeyran

96s-07 Toward a Political Theory of Environmental Policy / Marcel Boyer et Jean-Jacques Laffont

96s-06 Work Sharing and Producrivity : Evidence from a Natural Experiment / Paul Lanoie, François Raymond et Bruce Shearer

96s-05 Claims Reporting and Risk Bearing Moral Hazard in Workers' Compensation : The Canadian Context / Guylaine Baril et Paul Lanoie

96s-04 The Determinants of University Dropouts : A Sequential Decision Model with Selectivity Bias / Claude Montmarquette, Sophie Mahseredjian et Rachel Houle

96s-03 Solutions au stress financier : Un survol de la littérature / Jocelyn Martel

96s-02 The Politics and Regulation of Hydroelectricity : The Case of Quebec in the Thirties / Ruth Dupré, Michel Patry et Patrick Joly

96s-01 Cognition in Seemingly Riskless Choices and Judgments / Louis Lévy-Garboua et Claude Montmarquette

95s-51 Entry Blockading Locations / Marcel Boyer, Philippe Mahenc et Michel Moreaux

95s-50 Environmental Protection, Producer Insolvency and Lender Liability / Marcel Boyer et Jean-Jacques Laffont

95s-49 Stochastic Volatility / Eric Ghysels, Andrew Harvey et Eric Renault

95s-48 Is Workers' Compensation Disguised Unemployment Insurance? / Bernard Fortin, Paul Lanoie et Christine Laporte

95s-47 Asset and Commodity Prices with Multiattribute Durable Goods / Jérôme Detemple et Christos I. Giannikos

95s-46 Cohort Effects and Returns to Seniority in France / David N. Margolis

* Vous pouvez consulter la liste complète des publications du CIRANO et les publications elles-mêmes sur notre site World Wide Web à l'adresse suivante :

http://www.cirano.umontreal.ca/publication/page1.html 